\title{
Evolution of Countermeasures against Atmospheric Icing of Power Lines over the Past Four Decades and Their Applications into Field Operations
}

\author{
Stephan Brettschneider * and Issouf Fofana (D)
}

Citation: Brettschneider, S.; Fofana, I. Evolution of Countermeasures against Atmospheric Icing of Power Lines over the Past Four Decades and Their Applications into Field Operations. Energies 2021, 14, 6291. https://doi.org/10.3390/en14196291

Academic Editors: Abu-Siada Ahmed and Andrea Mariscotti

Received: 2 September 2021

Accepted: 27 September 2021

Published: 2 October 2021

Publisher's Note: MDPI stays neutral with regard to jurisdictional claims in published maps and institutional affiliations.

Copyright: (c) 2021 by the authors. Licensee MDPI, Basel, Switzerland. This article is an open access article distributed under the terms and conditions of the Creative Commons Attribution (CC BY) license (https:// creativecommons.org/licenses/by/ $4.0 /)$.
International Research Center for Atmospheric Icing and Power Systems Engineering (CENGIVRE), Université du Québec à Chicoutimi, 555 Boulevard de l'Université, Chicoutimi, QC G7H 2B1, Canada; Issouf_fofana@uqac.ca

* Correspondence: stephan_brettschneider@uqac.ca; Tel.: +1-418-545-5011; Fax: +1-418-545-5012

Abstract: The reliability and efficiency of power grids directly contribute to the economic well-being and quality of life of citizens in any country. This reliability depends, among other things, on the power lines that are exposed to different kinds of factors such as lightning, pollution, ice storm, wind, etc. In particular, ice and snow are serious threats in various areas of the world. Under certain conditions, outdoor equipment and hardware may experience various problems: cracking, fatigue, wear, flashover, etc. In actual fact, a variety of countermeasures has been proposed over the past decades and a certain number have been applied by utilities in various countries. This contribution presents the status and current trends of different techniques against atmospheric icing of power lines. A snapshot look at some significant development on this topic over the last four decades is addressed. Engineering problems in utilizing these techniques, their applications, and perspectives are also foreseen. The latest up-to-date review papers on the applications and challenges in terms of $\mathrm{PhD}$ thesis, journal articles, conference proceedings, technical reports, and web materials are reported.

Keywords: overhead power lines; atmospheric icing; power outage; anti-icing; de-icing; line design; passive devices; coatings; mechanical methods; thermal methods

\section{Introduction}

To reach the consumption areas, electricity often travels large distances through power transmission lines due to the remote location of most power plants, crossing different climatic environments. These transmission lines are often exposed to various stresses influencing their operation, causing in some cases different outages. Power grid infrastructures in many countries around the world are consequently impacted by ice and snow accretions. Some countries in the arctic region, such as Canada, the United States, Russia, Iceland, and Scandinavian countries, have been exposed to these problems since the deployment of electricity networks [1-3]. Additionally, power lines crossing mountainous areas are prone to ice and snow, for example, in China or Italy [4,5]. Furthermore, climate change leads to more and extreme weather events in various countries [3]. As the impact of ice and snow accretions is more intense for temperatures close to the freezing point, the occurrence of critical situations may not be limited to the known cold regions of our planet.

Associated to the ever-growing world's population and faster industry development, many power grid projects have been commissioned or are underway around the world. The impact of snow or ice events consequently gained importance. Extreme reliability is therefore demanded for electricity distribution. When failures occur, they inevitably lead to high repair costs, long downtime, and potential risks to human safety. Therefore, a variety of countermeasures against atmospheric icing of power lines were proposed in the past to avoid or at least to minimize power outages during such ice or snow events. Pohlman et al. [1] in 1982 firstly reviewed the various anti-icing and de-icing methods 
known at that moment. Since then, various other reviews and technical reports have been published [2,6-11]. In the framework of the present contribution, the evolution of the proposed countermeasures over the past four decades was analyzed by comparing these reviews. In the second part of the article, a few study cases focusing on the selection of methods for field applications or further investigations were examined based on the publications $[4,5,12-16]$.

It may be noted that it is not the intention of this article to provide detailed information on each individual anti-icing and de-icing method. This information can readily be found in the various publications cited in the article.

For the general understanding of the importance and possible impact of snow and icing events, some information on two examples of important cases of ice storms are provided. Furthermore, some general information on the distinction of anti-icing and de-icing methods as well as on the general impacts of snow and ice on power lines are included.

\subsection{Two Examples of Extreme Ice Storm Events}

Similar to any meteorological event, snow and ice storms do not occur on a regular basis. However, some areas of the world may experience these events more or less recurrently. Rarely, extreme icing events occur with disastrous impacts on a larger region. Two of such catastrophic events may be recalled here:

- In the first week of January 1998, up to $110 \mathrm{~mm}$ of ice accumulated in some parts of eastern Canada (southern Quebec including the city of Montreal, some eastern parts of Ontario). About 1500 high voltage line towers and 17,000 distribution poles had to be replaced. Approximately, 3 million people had lost electricity at the peak of the ice storm, and it took one month to reconnect the last customers [17]. Figures 1 and 2 illustrate the damage on the transmission and distribution networks during this event.

- At the end of January 2008, heavy wet snow and freezing ice precipitations were experienced for several days in parts of southern and central China. Over 100 of the $500 \mathrm{kV}$ power lines and about 340 of the $220 \mathrm{kV}$ power lines were interrupted [4]. Several millions of people were affected, and it took two to three weeks in some areas to completely restore the electrical power supply.

\subsection{Anti-Icing and De-Icing}

The literature uses commonly the two terms: "anti-icing" and "de-icing". The first term, "anti-icing", is used for the approach where it is intended to prevent any accumulation of snow or ice on the power lines. The second term "de-icing" identifies the approach where existing ice or snow accumulations are to be removed [2,8]. Some methods are efficient for one or the other approach. For example, icephobic coatings are a measure against ice buildup [8], whereas mechanical methods such as manual scraping or roller wheels are used to remove the ice or snow that was already accumulated [2]. Other methods such as heating of the conductor may be applied for both approaches [5,9]. More details on the distinction between anti-icing and de-icing methods can be found in the appendix B of [6] and in reference [11]. 


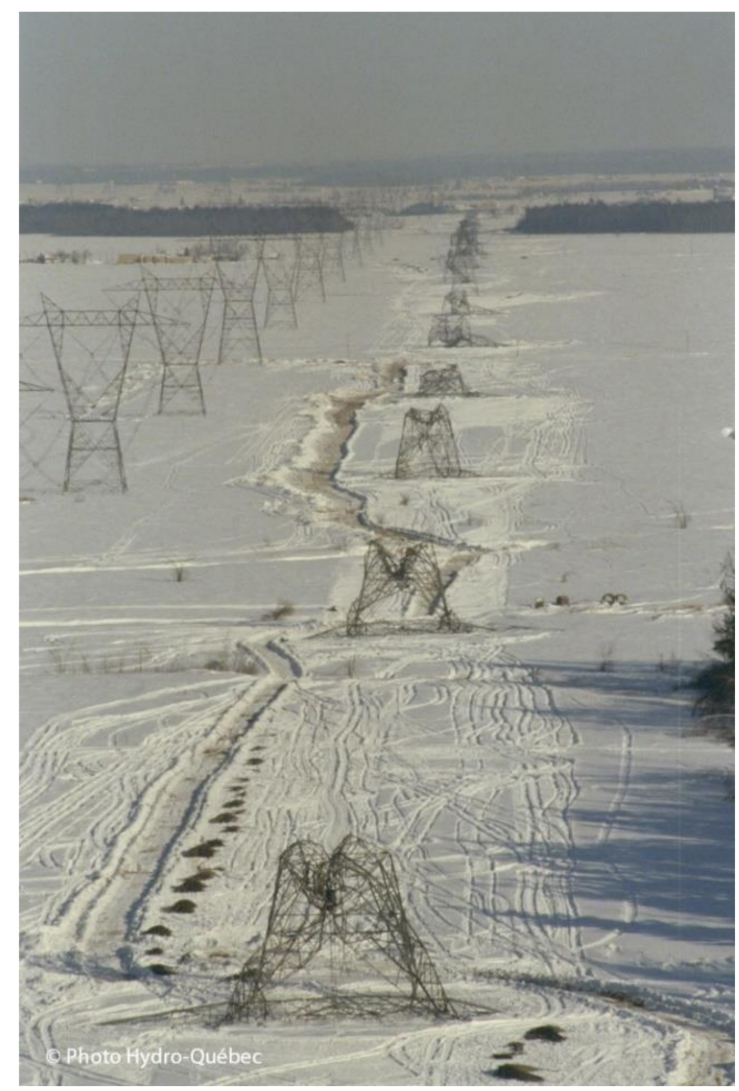

Figure 1. Example of icing impact on a high voltage transmission line (1998 Eastern Canada ice storm, credit: Photo Hydro-Québec).

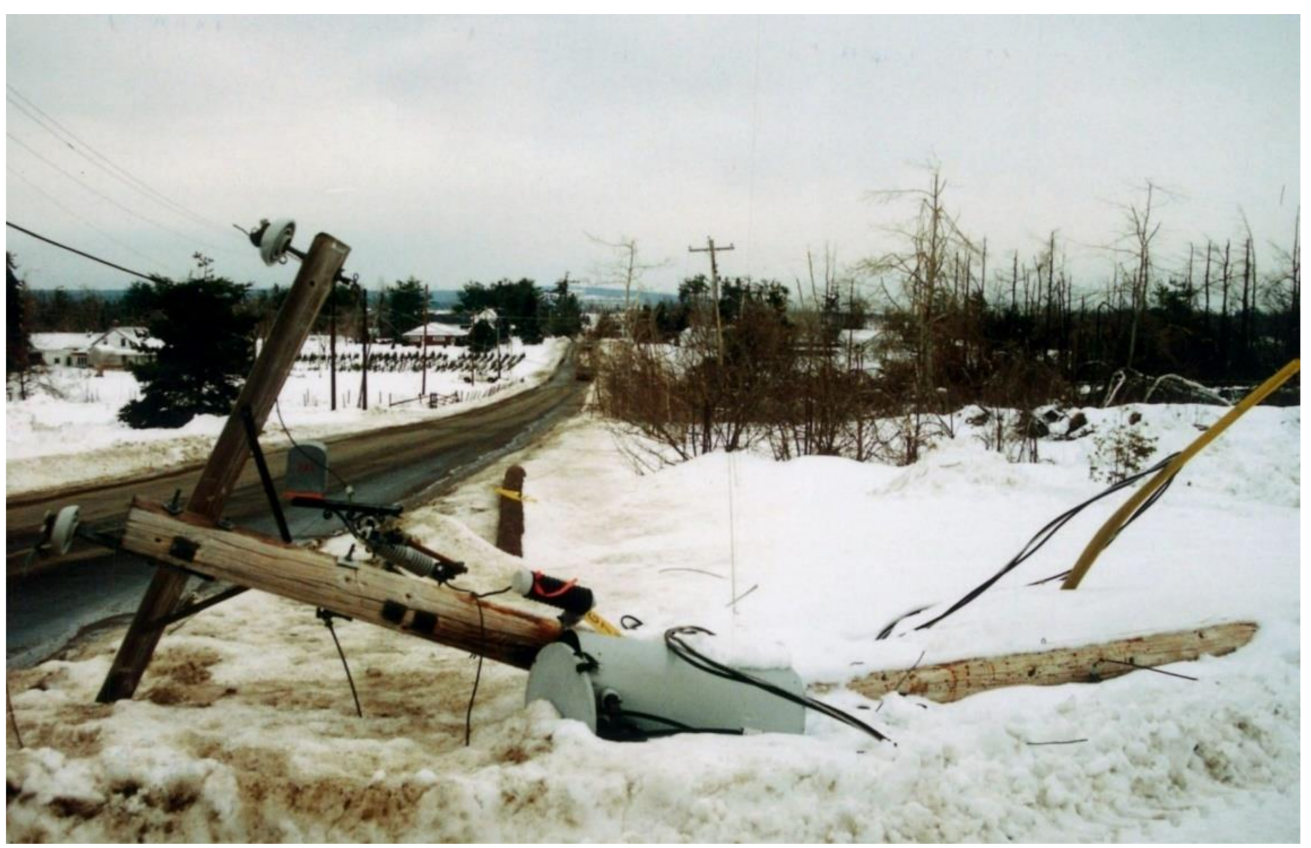

Figure 2. Example of icing impact on a medium voltage distribution line (1998 Eastern Canada ice storm, credit: private archive).

\subsection{Consequences of Ice and Snow Accumulations on Power Lines}

The impacts of ice or snow accumulations on power lines are already well documented by different authors, e.g., $[1,8,11]$. It should be mentioned here that the impacts for power lines are mainly of a mechanical nature. The increase in the static load is important due 
to the additional weight of ice or snow accumulations (for example, ref [15] mentions up to $100 \mathrm{~kg} / \mathrm{m}$ ) and it may push the supporting structures to their limits. Furthermore, dynamic forces may become problematic, either due to galloping of conductors or ground wires or during the shedding of the additional weight. If two adjacent spans of a standard tower shed their ice load at different moments, the tower may be subjected to lateral forces beyond its designed limit.

Electrical failure may also occur in some cases [11]. Conductors of different phases may get close or in contact due to unequal accumulation or dynamic wind forces. Induced corona discharges may increase power losses or electromagnetic interferences. Finally, ice-covered insulators may experience flashover, especially if the line is subject to pollution or salt deposit (natural from the sea or artificial near highways) [11]. A review of the present stage of knowledge of outdoor insulator flashover is presented in [3].

\section{Comparison Approach}

Various anti-icing and de-icing methods have been developed in different countries and important research efforts have been deployed for several decades [9]. This article presents a comparative analysis of the different countermeasures that have been proposed to protect the power line infrastructure based on the following two approaches:

First, a comparative study was carried by analyzing a certain number of publications and technical reports that reviewed the proposed countermeasures over the past four decades. This comparison was carried out with the following objectives:

- To provide a concise overview of various proposed countermeasures;

- To analyze the evolution of countermeasures in the past decades;

- To examine if a catastrophic event (such as the big ice storm in Eastern Canada in January 1998) had an impact on the development of countermeasures.

The following comprehensive references were considered for this part of the study. The selection includes publications before and after the 1998 Eastern Canada ice storm:

- $\quad$ Reference [1] published in 1982 is considered by several authors as the first known review focusing on anti-icing and de-icing methods for overhead power lines.

- $\quad$ Reference [2] summarizes a technical report that was prepared for Hydro-Québec before the 1998 ice storm in eastern Canada.

- References [6] is a detailed technical report that was published in 2002, about four years after the 1998 ice storm in eastern Canada.

- $\quad$ References [7,8] were published, respectively, in 2005 and 2008 by the same team of authors. They described and classified various anti-icing and de-icing methods as a result of the intense research activities during the years after the 1998 ice storm in Eastern Canada.

- $\quad$ Reference [9] was written by an international expert committee in the framework of a CIGRE working group in 2010. It can be seen as a milestone for the documentation of the anti-icing and de-icing methods reporting in detail the knowledge at the moment of publication.

- Reference [10] is a master thesis published in 2018 on the topic of this study, thus some years after the preceding analyzed documents.

- Reference [11] is a recent publication that provides technical content to the power industry. It offers a comprehensive overview of the present knowledge of various anti-icing and de-icing technologies. Besides the countermeasures for power lines, it also covers the possible impacts and countermeasures for insulators.

The results of this comparative analysis are presented in Section 3.

Second, the application and integration of countermeasures into field operations are reported by reviewing various references in order to identify those, which found real life applications. The actions of Hydro Québec after the 1998 Eastern Canada ice storm could be analyzed using various publicly available publications (e.g., annual reports). Other 
studies with recommendations for future applications were analyzed for China, Italy, and Norway.

The following references were considered for this part of the study:

- References [12-14] present the methods that were selected by Hydro-Québec for further analyses after the Eastern Canada ice storm in 1998. The references include a ranking of the selected methods according to various criteria, including cost, complexity, implementation delay and reliability. This evaluation was carried out in order to help Hydro-Québec deciding which methods should be implemented into the field operations.

- Reference [5] includes a concise overview of various methods and it reports details of the method that was selected for future applications in parts of the Italian power grid.

- Reference [15] includes a selection of methods that are considered applicable for the specific situation in Norway. It presents a ranking for some selected methods addressing recommendations for future applications in the Norwegian power grid.

- References $[4,16]$ report overviews and research efforts in China after the 2008 ice storm. Each publication provides a recommendation on the method that should be investigated for further research and optimization.

The results for this second part are presented in Section 4.

\section{Comparison of the Various Countermeasures Proposed over the Last Four Decades against Power Line Icing}

\subsection{Classification of Various Countermeasures}

In order to compare various countermeasures that were proposed over the past four decades, different anti-icing and de-icing methods are compiled in Table 1. Each analyzed publication is represented by a column. The two catastrophic ice storms (1998 in Eastern Canada and 2008 in southern and central China) were also included as time reference.

Different approaches may be used to classify the anti-icing and de-icing technologies [7,9]. This study started by adopting four groups that were presented in reference [9]: passive methods, active coatings and devices, mechanical methods, and thermal methods. During compilation, a separate group was formed for line design considerations as previously done in references $[6,11]$. The group of passive methods was split into two separate groups for passive devices and passive coatings as their effects on the ice-and snow accumulations are different. A seventh group for miscellaneous methods was added in order to list some proposed countermeasures that did not seem to fit in the other groups (as previously done by reference [2]).

A brief description for each group of countermeasures is given next. The reader is encouraged to read references $[1,2,6-11]$ for detailed information on each individual anti-icing and de-icing method.

\subsubsection{Line Design Considerations}

These considerations can be applied for new line constructions or the reconstruction of heavily damaged lines in order to prevent either ice or snow accumulations (by avoiding critical regions or by putting the lines underground) or to strengthen the withstand capability of the lines (stronger towers or increase in distance between phases). The choice of the conductor or bundle may have different effects; it can either influence the amount of accumulation, the speed of ice shedding, or the torsional strength of power lines. 
Table 1. Comparison of various anti-icing and de-icing methods proposed over the last four decades (for time reference, the table also includes the two catastrophic icing event).

\begin{tabular}{|c|c|c|c|c|c|c|c|c|c|c|}
\hline & Countermeasure & {$[1]-1982$} & {$[2]-1996$} & & {$[6]-2002$} & {$[7,8] 2005 /-2008$} & & {$[9]-2010$} & {$[10]-2018$} & {$[11]-2020$} \\
\hline 1. Line Design & & & & & & & & & & \\
\hline 1.1 Improved line routing & & & & & $\mathrm{X}$ & & & & & $\mathrm{X}$ \\
\hline 1.2 Underground cables & & & & & $\mathrm{X}$ & & & & & $\mathrm{X}$ \\
\hline & 1.3.1 Using separate structures for each phase & & & & & & & $\mathrm{X}$ & & \\
\hline 1.3 Measures to avoid & 1.3.2 Modifying crossarms (longer middle crossarms) & & & & & & & $\mathrm{X}$ & & \\
\hline interphase-short-circuits & 1.3.3 Modify circuit spacing & & & & & & & $\mathrm{X}$ & & \\
\hline & 1.3.4 Rearranging phase configuration & & & & & & & $\mathrm{X}$ & & \\
\hline 1.4 Mechanical & 1.4.1 Stronger towers & & & & $\mathrm{X}$ & & & $\mathrm{X}$ & & $\mathrm{X}$ \\
\hline reinforcement & 1.4.2 Anti-cascading towers & & & & $\mathrm{X}$ & & & & & $\mathrm{X}$ \\
\hline 1.5 No ground wire (but & dition of special surge arrestors) & & & & $\mathrm{X}$ & & & & & $\mathrm{X}$ \\
\hline 1.6 Choice of conductor & 1.6.2 Optimised simple conductor & & & & & & & & & \\
\hline & 1.6.3 Increased number in bundle & & & & & & & $\mathrm{X}$ & & $\mathrm{X}$ \\
\hline 2. Passive Devices & & & & & & & & & & \\
\hline 2.1 Counterweights (anti & otation device) & & $X$ & ह్ & $\mathrm{X}$ & $X$ & . & $\mathrm{X}$ & $\mathrm{X}$ & $\mathrm{X}$ \\
\hline 2.2 Snow rings, wires anc & Teflon tapes & & $X$ & ङ & & & $\tilde{\sigma}$ & $X$ & $X$ & $X$ \\
\hline 2.3 Interphase spacers & & & & & & $X$ & & $X$ & & $X$ \\
\hline 2.4 Spacer dampers & & & & & & $\mathrm{X}$ & 5 & & & $X$ \\
\hline 2.5 Load reducing device & mechanical fuses, fasteners & & $\mathrm{X}$ & $\frac{5}{3}$ & $\mathrm{X}$ & & I & & & $\mathrm{X}$ \\
\hline 2.6 Aeolian shedding & & & $\mathrm{X}$ & 离 & $\mathrm{X}$ & & के & & & \\
\hline 3. Passive Coatings & & & & & & & & & & \\
\hline 3.3 Freezing point depres & ant fluids & $X$ & $\mathrm{X}$ & & $\mathrm{X}$ & $\mathrm{X}$ & 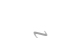 & & & $\mathrm{X}$ \\
\hline 3.4 Icephobic coatings & & $\mathrm{X}$ & $\mathrm{X}$ & E & $\mathrm{X}$ & $\mathrm{X}$ & $\therefore$ & $\mathrm{X}$ & & $\mathrm{X}$ \\
\hline 3.5 Hydrophobic and sur & rhydrophobic coatings & & $\mathrm{X}$ & 5 & & $\mathrm{X}$ & & $\mathrm{X}$ & & $\mathrm{X}$ \\
\hline 3.6 Black coatings / Heat & bsorbent coatings & & $\mathrm{X}$ & & $\mathrm{X}$ & & 5 & & & $X$ \\
\hline 3.7 Chemically reactive $c$ & ting & & & & $\mathrm{X}$ & & & & & \\
\hline 4. Active Coatings & & & & $\ddot{ت}$ & & & & & & \\
\hline 4.1 Addition of ferroelect & c material (high frequency injection) & & & & $\mathrm{X}$ & $\mathrm{X}$ & $\underset{\infty}{\infty}$ & $\mathrm{X}$ & $\mathrm{X}$ & $X$ \\
\hline 4.2 LC spiral rods (ferron & gnetic spirals) & & $\mathrm{X}$ & & $\mathrm{X}$ & $\mathrm{X}$ & 8 & $\mathrm{X}$ & $\mathrm{X}$ & $\mathrm{X}$ \\
\hline 4.3 Heated tracers & & & $\mathrm{x}$ & ळ & $\mathrm{x}$ & $\mathrm{X}$ & & $\mathrm{X}$ & & \\
\hline 4.4 Ice electrolysis & & & & & & $X$ & & $\mathrm{X}$ & & $X$ \\
\hline 4.5 Piezoelectric polymer & (PVDF) & & & & $X$ & $\mathrm{X}$ & & & & $\mathrm{X}$ \\
\hline 4.6 Shape memory alloys & & & $\mathrm{X}$ & & $\mathrm{X}$ & & & & & \\
\hline 5. Mechanical Methods & & & & & & & & & & \\
\hline & 5.1.1 Roller wheels or scraping & $X$ & $X$ & & $\mathrm{X}$ & $\mathrm{X}$ & & $X$ & $\mathrm{X}$ & $\mathrm{X}$ \\
\hline & 5.1.2 Manual shock wave & $X$ & $\mathrm{X}$ & & & $\mathrm{X}$ & & $\mathrm{X}$ & & $X$ \\
\hline 1 1 in Min & 5.1.3 Tensioning and releasing & & $\mathrm{X}$ & & $\mathrm{X}$ & & & & & \\
\hline 5.1 Line Maintenance & 5.1.4 De-icer Actuated by Cartridge (DAC) & & $\mathrm{X}$ & & & $\mathrm{X}$ & & $\mathrm{X}$ & & $\mathrm{X}$ \\
\hline & 5.1.5 Helicopter (wooden pole or rope with knots) & & $\mathrm{X}$ & & $\mathrm{X}$ & $\mathrm{X}$ & & $\mathrm{X}$ & $X$ & \\
\hline & 5.1.6 Remotely Operated Vehicle (ROV) (Scraping) & & & & & $\mathrm{X}$ & & $\mathrm{X}$ & & $\mathrm{X}$ \\
\hline
\end{tabular}


Table 1. Cont.

\begin{tabular}{|c|c|c|c|c|c|c|c|c|c|}
\hline Countermeasure & [1]-1982 & [2]-1996 & & {$[6]-2002$} & {$[7,8] 2005 /-2008$} & & [9]-2010 & [10]-2018 & [11]-2020 \\
\hline 5.2 Pneumatic Hammer & & $\mathrm{X}$ & & $\mathrm{X}$ & $\mathrm{X}$ & & $\mathrm{X}$ & & \\
\hline 5.3 Eletro-impulse method (EIDI) & & $\mathrm{X}$ & & $X$ & $X$ & & $X$ & & \\
\hline 5.4 Ice-shedder device (induced vibrations) & & $X$ & & $X$ & $\mathrm{X}$ & & $X$ & $\mathrm{X}$ & $\mathrm{X}$ \\
\hline 5.5 Twisting device & & & & & $X$ & & $\mathrm{X}$ & & \\
\hline 5.6 High-magnitude short circuit method (for bundled conductors) & & & & $\mathrm{X}$ & $\mathrm{X}$ & & $\mathrm{X}$ & $\mathrm{X}$ & $\mathrm{X}$ \\
\hline 6. Thermal Methods & & & & & & $\Xi$ & & & \\
\hline 6.1.1 Load shifting (Load transfer) method & $\mathrm{X}$ & $\mathrm{X}$ & & $X$ & $\mathrm{X}$ & 辛 & $\mathrm{X}$ & $\mathrm{X}$ & $\mathrm{X}$ \\
\hline 6.1.2 On-load De-Icer method (ONDI) (phase shifting) & & & है & & $\mathrm{X}$ & 0 & $\mathrm{X}$ & $\mathrm{X}$ & $\mathrm{X}$ \\
\hline 6.1.3 Reactive Current De-icing & & & है & & & & & $\mathrm{X}$ & \\
\hline 6.2.1 Reduced (medium) voltage short-circuit method & & $\mathrm{X}$ & 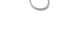 & $\mathrm{X}$ & $\mathrm{X}$ & ह & $\mathrm{X}$ & $\mathrm{X}$ & $\mathrm{X}$ \\
\hline 6.2.3 DC current method for AC-lines & & & I & $\mathrm{X}$ & $\mathrm{X}$ & ב & $X$ & $\mathrm{X}$ & $\mathrm{X}$ \\
\hline 6.3 DC-Line De-icing & & & 苋 & $X$ & & $\sum^{\infty}$ & & & \\
\hline 6.4 High frequency electric field method & & & 昰 & $X$ & $\mathrm{X}$ & ذِّ & $X$ & $\mathrm{X}$ & \\
\hline 6.5 Contactor load transfer method (bundle shifting / current re-distribution) & & & & $X$ & $\mathrm{X}$ & 通 & $\mathrm{X}$ & $\mathrm{X}$ & $\mathrm{X}$ \\
\hline 6.6 Pulse electrothermal de-icer method & & & $\Xi$ & $\mathrm{X}$ & $\mathrm{X}$ & & $\mathrm{X}$ & & $\mathrm{X}$ \\
\hline $\begin{array}{ll}6.7 .1 \text { Infrared waves } \\
\end{array}$ & & $\mathrm{X}$ & & & & & & & \\
\hline 6.7.2 Radio waves radiation ext. heat source & & $\mathrm{X}$ & & $\mathrm{X}$ & $\mathrm{X}$ & $\Xi$ & $\mathrm{X}$ & & \\
\hline 6.7.3 Steam generating device & $\mathrm{X}$ & & E & & $\mathrm{X}$ & & $\mathrm{X}$ & $\mathrm{X}$ & \\
\hline 6.7.4 Ultrasonic De-icing & & $\mathrm{X}$ & के & & & E & & $\mathrm{X}$ & \\
\hline 6.7.5 Hot Gas & & $\mathrm{X}$ & & & & 竧 & & & \\
\hline 6.7.6 Hot Water/Anti-icing fluids & & $\mathrm{X}$ & & & & & & & \\
\hline 7.1 Drop freezing before impact & & $\mathrm{X}$ & & $\mathrm{X}$ & & : & & & \\
\hline 7.2 Drop heating before impact & & $\mathrm{X}$ & $\infty$ & $X$ & & & & & \\
\hline 7.3 Corona discharges & & $\mathrm{X}$ & حे & $\mathrm{X}$ & & & & & \\
\hline 7.4 Electro-congelation & & $\mathrm{X}$ & & & & 8 & & & \\
\hline 7.5 Development of ice-resistant conductors & & & & & & & & & \\
\hline 7.6 Laser De-Icing & & $X$ & & & & & & & \\
\hline 7.7 Pneumatic air boots & $\mathrm{X}$ & $\mathrm{X}$ & & $\mathrm{X}$ & & & & & \\
\hline 7.8 Asymmetric operation of 3-phase power lines & & & & & & & & & \\
\hline
\end{tabular}




\subsubsection{Passive Devices}

These devices do not prevent or reduce the amount of ice or snow that may accumulate on power lines, but reduce the negative impacts of these accumulations. For example, counterweights will lead to non-cylindrical ice deposits that will shed faster. Interphase spacers will maintain the distance between phase conductors even if they are not loaded with the same amount of ice or snow. Due to these kinds of indirect effects, problems such as phase-to-phase short-circuits or tower collapse can be avoided.

\subsubsection{Passive Coatings}

Coatings are applied to the conductor to avoid or at least limit ice or snow accumulations. Passive coatings do not require any external energy, but modify the surface properties of the conductors with the aim of weakening the adhesion forces of water droplets, ice or snow on the conductor surface.

\subsubsection{Active Coatings}

Active coatings use external energy to prevent or limit the accumulation of ice or snow on the conductor surface. Various principles are proposed to prevent or reduce any accumulation, such as heating due to the increase in losses, addition of heating tracers or the reduction in ice adhesion forces through ice electrolysis.

\subsubsection{Mechanical Methods}

Mechanical methods use different principles to break off the accumulated ice or snow. The forces required to break the ice may be applied by linemen with isolated poles or tools pulled by ropes or also from helicopters. Other methods consider apparatus that are installed on the lines temporarily or on a permanent basis. For bundled conductors, the force to break the ice may be generated by a temporary short circuit.

\subsubsection{Thermal Methods}

Thermal methods use different principles to heat conductors and ground wires in order to avoid any accumulation of ice or snow or to melt off existing accumulations. Different energy sources may be used; for example, the energy of the power network itself through load shifting, external current sources such as DC injection or high frequency injection or other external heat sources.

\subsubsection{Miscellaneous Methods}

This last group covers methods that were reported in some reviews and that did not seem to fit in any of the six preceding groups [2]. Some methods are still at a conceptual stage and their feasibility was not yet validated. Other methods were mentioned, but their applicability to power lines does not seem to be efficient [2]. The method 7.8 for asymmetrical operation of a three-phase power line was not included in any of the analyzed review publications, but was mentioned during the public hearing process for the authorization of the construction of the Levis de-icer project by Hydro-Québec [18]. It was therefore included in the last group of this study.

\subsection{Comparative Analysis over the Last Four Decades}

Figure 3 shows the chronology of the analysed review papers in relation to the two catastrophic icing events. It can be recognized that the number of proposed anti-icing and de-icing methods increased significantly between the 1980s and 1990s, but there is no remarkable increase in the number of countermeasures during the last three decades. A large variety of methods for anti-icing and de-icing was already proposed in the 1990s, before the two catastrophic icing events in 1998 and 2008. However, the compilation in Table 1 does not show the degree of advancement of the individual methods at the moment of publication. For example, icephobic coatings were already mentioned as a potential countermeasure by Laforte et al. in 1996 [2]. At that time, the stage of advancement for this 
passive method was indicated as "in development". Intensive research efforts have led to important advancements in the field of icephobic coatings and surface treatments, as witnessed by recent CIGRE working group activities $[19,20]$. However, additional efforts in research and development are still required in order to come up with effective and durable solutions for practical applications [20].

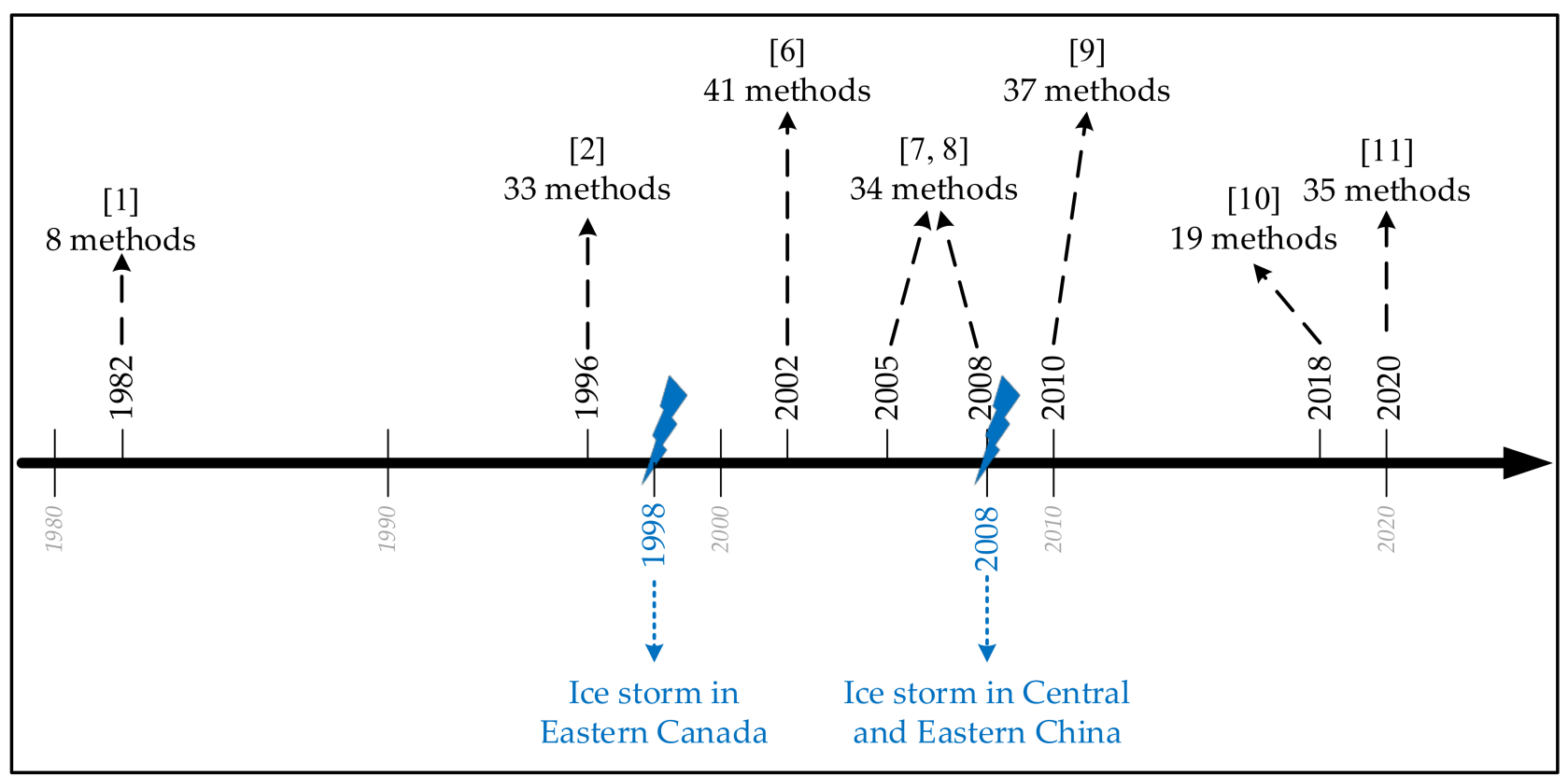

Figure 3. Chronology of the analysed review papers in relation to the two catastrophic icing events.

The compilation in Table 1 allows two more observations. The analyzed documents before the 1998 Eastern Canada ice storm [1,2] did not include any countermeasure in the field of line design (group 1 in Table 1). Perhaps these methods were initially not considered as countermeasures, because no additional equipment is required. Nevertheless, it can be noted that the knowledge on the positive effects of line design considerations has increased with the experiences gained from various icing events over the past few decades. As shown in the second part of the study (see Section 4.2), several line design measures have been implemented after the 1998 ice storm in Eastern Canada. Reference [11] indicates that these approaches present the best prevention technique for new constructions, but should be seen as complementary to the other countermeasures in order to obtain an optimized protection of power lines against icing events.

The second observation shows that in more recent articles, the miscellaneous methods (group 7 in Table 1) that were proposed in the two documents of 1996 and 2002 [2,6] were no longer included. One might understand that the applicability of these more theoretical approaches has not been demonstrated and that research institutions and electric utilities focused their efforts on the development of already known countermeasures that showed greater potential for practical applications in the field.

\section{Selection of Countermeasures for the Integration into Field Operations or for Further Investigations}

Four example cases were reviewed for the selection or recommendation of counter measures for field application. The results are compiled in Table 2. The first column is similar to the one of Table 1 and lists the countermeasures that were proposed over the past four decades. The other columns present the various methods that were considered in the four example cases. The bold and capital letters indicate the methods that were selected or recommended for field applications or further investigations. 


\subsection{Technology Integration within Hydro-Québec after the 1998 Eastern Canada Ice Storm}

References [12-14] show the analysis performed by Hydro-Québec after the 1998 ice storm in Eastern Canada. Eleven countermeasures were considered and a detailed evaluation of each method using several criteria was carried out. This analysis allowed assigning a score to each method and establishing a ranking. The numbers in the second column of Table 2 represent the results of this ranking. The two methods with the highest scores were:

- The highest score was obtained for the thermal method by load shifting (method 6.1.1). However, this method can only be applied to a certain number of power lines with voltage levels varying from $49 \mathrm{kV}$ to $315 \mathrm{kV}$, but it is not suitable for the $735 \mathrm{kV}$ network of Hydro-Québec [14].

- The second score was obtained for the thermal method by DC current injection (method 6.2.3). The decision was made to install a large DC source at a centrally located substation that could inject DC current into the high voltage power lines and ground wires. A technology was chosen that could also be used as a static var compensator (SVC) throughout the year, which would help making the project economically viable. However, the implementation of this de-icer project was a complex task and it is still ongoing at the present time. The analysis of annual reports published by Hydro-Québec allowed tracing a timeline for the various steps:

- Approval for the project was obtained in August 2004 [21].

- The engineering for the de-icer project was completed in 2005 [22].

- In 2008, the commissioning of the de-icer project was completed [23].

- However, the de-icer could not be used until today. One of the main reasons for this blockage is the risk of ice pieces falling onto highways and damaging cars during the de-icing period. Therefore, Hydro-Québec started installing the LC-spirals (method 4.2) on the power lines above highways in 2017 [24]. These installations are relatively difficult to schedule as the highways have to be closed temporarily. The installation efforts are scheduled through 2023 in order to cover all critical highway crossings.

Hydro-Québec did not only rely on these two methods. The following other countermeasures were integrated into field operations on the Hydro-Québec power network:

- In 2010, Hydro-Québec stared to test the de-icer actuated by cartridge (DAC, method 5.1.4) for the de-icing of ground wires [25]. From 2012, this tool was adapted for general use [26].

- In 2012, Hydro-Québec reported that the robot LINEROV for mechanical de-icing of power lines (method 5.1.6) was used with success on several occasions [26].

Furthermore, several line design considerations are adapted to strengthen the network against impacts of future winter storms [27]:

- Reconstructed lines were built with improved mechanical strength in order to withstand higher ice loads (method 1.4.1).

- Anti-cascading towers were included in critical line sections in order to limit damage that could result from the collapse of towers (method 1.4.2).

- On the distribution network, poles and their anchoring were strengthened. In the case of a catastrophic event, only the crossarm and conductors could fall (method 2.5). This makes reconstruction easier and faster.

- Some additional new line sections were constructed in order to create additional meshed loops in the power network that provide increased redundancy for the power supply.

- The vegetation control program has been enhanced to prevent falling iced trees from causing power outages in the distribution network.

Another example for the improvement of network design is the construction of a new line for the interconnection of a windfarm in 2011. This line had to be constructed in an 
area with particular weather conditions that favour the accumulation of important ice loads. The following line design considerations were applied in this particular case [28]:

- $\quad$ The type of towers selected can withstand higher ice loads (method 1.4.1).

- The line does not have a ground wire, but surge arresters with external spark gap were installed (method 1.5).

- The type of conductor selected had superior mechanical strength (method 1.6).

Table 2. Summary of the countermeasures that were selected for application or future investigation in four different countries.

\begin{tabular}{|c|c|c|c|c|c|}
\hline & Countermeasure & $\begin{array}{c}{[12-14]-} \\
\text { Canada- } \\
2004\end{array}$ & $\begin{array}{c}{[5]-} \\
\text { Italy- } \\
2019\end{array}$ & $\begin{array}{c}{[15]-} \\
\text { Norway- } \\
2019\end{array}$ & $\begin{array}{c}4,16,29,30]- \\
\text { China- } \\
2010-2015\end{array}$ \\
\hline \multicolumn{6}{|l|}{ 1. Line Design } \\
\hline \multicolumn{6}{|l|}{ 1.1 Improved line routing } \\
\hline \multicolumn{6}{|l|}{1.2 Underground cables } \\
\hline \multirow{4}{*}{$\begin{array}{l}\text { 1.3 Measures to avoid } \\
\text { interphase-short-circuits }\end{array}$} & 1.3.1 Using separate structures for each phase & & & & \\
\hline & $\begin{array}{l}\text { 1.3.2 Modifying crossarms } \\
\text { (longer middle crossarms) }\end{array}$ & & & & \\
\hline & 1.3.3 Modify circuit spacing & & & & \\
\hline & 1.3.4 Rearranging phase configuration & & & & \\
\hline \multirow{2}{*}{$\begin{array}{l}1.4 \text { Mechanical } \\
\text { reinforcement }\end{array}$} & 1.4.1 Stronger towers & 7 & & & \\
\hline & 1.4.2 Anti-cascading towers & & & & \\
\hline \multicolumn{2}{|c|}{1.5 No ground wire (but addition of special surge arrestors) } & & & $\mathrm{X}$ & \\
\hline \multirow{3}{*}{$\begin{array}{l}\text { 1.6 Choice of conductor } \\
\text { or bundle }\end{array}$} & $\begin{array}{l}\text { 1.6.1 Compact design (trapezoidal or } \\
\text { z-shaped strands) }\end{array}$ & 5 & & $X$ & \\
\hline & 1.6.2 Optimised simple conductor & 4 & & $\mathrm{X}$ & \\
\hline & 1.6.3 Increased number in bundle & & & $\mathrm{X}$ & \\
\hline \multicolumn{6}{|c|}{ 2. Passive Devices } \\
\hline \multicolumn{2}{|c|}{ 2.1 Counterweights (anti-rotation device) } & & $\mathbf{X}$ & $\mathrm{X}$ & \\
\hline \multicolumn{2}{|c|}{2.2 Snow rings, wires and Teflon tapes } & & $\mathrm{X}$ & $\mathrm{X}$ & \\
\hline \multicolumn{2}{|c|}{2.3 Interphase spacers } & & $\mathbf{X}$ & & \\
\hline \multicolumn{2}{|c|}{2.4 Spacer dampers } & & & & \\
\hline \multicolumn{2}{|c|}{ 2.5 Load reducing devices, mechanical fuses, fasteners } & 10 & & & \\
\hline \multicolumn{6}{|c|}{ 2.6 Aeolian shedding } \\
\hline \multicolumn{6}{|c|}{ 3. Passive Coatings } \\
\hline \multicolumn{6}{|c|}{3.1 Industrial viscous liquids } \\
\hline \multicolumn{6}{|c|}{3.2 Heterogeneous polymer coatings } \\
\hline \multicolumn{6}{|c|}{ 3.3 Freezing point depressant fluids } \\
\hline \multicolumn{2}{|c|}{3.4 Icephobic coatings } & 8 & $\mathrm{X}$ & $\mathrm{X}$ & \\
\hline \multicolumn{6}{|c|}{ 3.5 Hydrophobic and superhydrophobic coatings } \\
\hline \multicolumn{6}{|c|}{ 3.6 Black coatings / Heat absorbent solid coatings } \\
\hline \multicolumn{6}{|c|}{ 3.7 Chemically reactive coating } \\
\hline 4. Active Coatings & & & & & \\
\hline 4.1 Addition of ferroelect & naterial (high frequency injection) & & $\mathrm{X}$ & & \\
\hline 4.2 LC spiral rods (ferron & etic spirals) & & $\mathrm{X}$ & $\mathbf{X}$ & \\
\hline 4.3 Heated tracers & & & & & \\
\hline 4.4 Ice electrolysis & & & & & \\
\hline 4.5 Piezoelectric polymer & JDF) & & & & \\
\hline 4.6 Shape memory alloys & & & & & \\
\hline 5. Mechanical Methods & & & & & \\
\hline & 5.1.1 Roller wheels or scraping & & $\mathrm{X}$ & & \\
\hline & 5.1.2 Manual shock wave & & $\mathrm{X}$ & & \\
\hline & 5.1.3 Tensioning and releasing & & & & \\
\hline 5.1 Line Maintenance & 5.1.4 De-icer Actuated by Cartridge (DAC) & & & & \\
\hline & $\begin{array}{l}\text { 5.1.5 Helicopter (wooden pole or rope } \\
\text { with knots) }\end{array}$ & & & $X$ & \\
\hline & 5.1.6 Remotely Operated Vehicle (ROV) & & & $\mathrm{X}$ & $\mathbf{X}$ \\
\hline 5.2 Pneumatic Hammer & & & & & \\
\hline 5.3 Electro-impulse meth & EIDI) & & & & $X$ \\
\hline 5.4 Ice-shedder device (in & ed vibrations) & & $\mathrm{X}$ & & \\
\hline 5.5 Twisting device & & & $\mathrm{X}$ & & \\
\hline 5.6 High-magnitude shor & cuit method (for bundled conductors) & 6 & & & \\
\hline
\end{tabular}


Table 2. Cont.

\begin{tabular}{|c|c|c|c|c|c|}
\hline & Countermeasure & $\begin{array}{c}{[12-14]-} \\
\text { Canada- } \\
2004\end{array}$ & $\begin{array}{c}{[5]-} \\
\text { Italy- } \\
2019\end{array}$ & $\begin{array}{c}{[15]-} \\
\text { Norway- } \\
2019\end{array}$ & $\begin{array}{c}4,16,29,30]- \\
\text { China- } \\
\text { 2010-2015 }\end{array}$ \\
\hline \multicolumn{6}{|l|}{ 6. Thermal Methods } \\
\hline \multirow{3}{*}{$\begin{array}{l}6.1 \text { Increase of line current } \\
\text { using the network }\end{array}$} & 6.1.1 Load shifting (Load transfer) method & 1 & $X$ & $\mathrm{X}$ & $\mathrm{X}$ \\
\hline & $\begin{array}{l}\text { 6.1.2 On-load De-Icer method (ONDI) } \\
\text { (phase shifting) }\end{array}$ & & & & $X$ \\
\hline & 6.1.3 Reactive Current De-icing & & $\mathbf{X}$ & & $\mathrm{X}$ \\
\hline \multirow{3}{*}{ 6.2 External current source } & $\begin{array}{l}\text { 6.2.1 Reduced (medium) voltage } \\
\text { short-circuit method }\end{array}$ & 3 & $X$ & $X$ & $X$ \\
\hline & $\begin{array}{l}\text { 6.2.2 Ground wire de-icing method } \\
\text { (MV short circuit) }\end{array}$ & & & $X$ & \\
\hline & 6.2.3 DC current method for AC-lines & 2 & & $\mathrm{X}$ & $\mathbf{X}$ \\
\hline \multicolumn{2}{|c|}{ 6.3 DC-Line De-icing } & & & & $\mathbf{X}$ \\
\hline \multicolumn{2}{|c|}{ 6.4 High frequency electric field method } & & & $\mathbf{X}$ & $X$ \\
\hline \multicolumn{2}{|c|}{ 6.5 Contactor load transfer (bundle shifting / current re-distribution) } & 11 & & $\mathbf{X}$ & $\mathbf{X}$ \\
\hline \multicolumn{2}{|c|}{ 6.6 Pulse electrothermal de-icer method } & & & & $\mathrm{X}$ \\
\hline \multirow{6}{*}{$\begin{array}{l}6.7 \text { Various external } \\
\text { heat sources }\end{array}$} & 6.7.1 Infrared waves & & & & $\mathrm{X}$ \\
\hline & 6.7.2 Radio waves radiation ext. heat source & & & & \\
\hline & 6.7.3 Steam generating device & & & & \\
\hline & 6.7.4 Ultrasonic De-icing & & & & \\
\hline & 6.7.5 Hot Gas & & & & \\
\hline & 6.7.6 Hot Water/Anti-icing fluids & & & & \\
\hline \multicolumn{6}{|l|}{ 7. Miscellaneous Methods } \\
\hline \multicolumn{6}{|l|}{ 7.1 Drop freezing before impact } \\
\hline \multicolumn{6}{|l|}{ 7.2 Drop heating before impact } \\
\hline \multicolumn{6}{|l|}{7.3 Corona discharges } \\
\hline \multicolumn{6}{|c|}{ 7.4 Electro-congelation } \\
\hline \multicolumn{2}{|c|}{ 7.6 Development of ice-resistant conductors } & 9 & & & \\
\hline \multicolumn{2}{|c|}{ 7.7 Laser De-Icing } & & & & $\mathrm{X}$ \\
\hline \multicolumn{2}{|c|}{7.8 Pneumatic air boots } & & & & \\
\hline 7.9 Asymmetric operation of & -phase power lines & & & & \\
\hline
\end{tabular}

\subsection{Recent Applicability Studies in Italy}

Even if Italy is not an arctic country, it experiences major power outages from time-totime, mainly due to wet snow accretions. Reference [5] presented an analysis of various anti-icing measures for the Italian power system including recommendations for the implementation of a new method. Until now, two passive methods have already been in use: in 2019, about 20,000 counterweights (method 2.1) were installed on $2500 \mathrm{~km}$ of $132 \mathrm{kV}$ lines, which led to a significant reduction in power outages due to snow overload. As the second countermeasure, interface spacers (method 2.3) were first installed on some critical spans of $132 \mathrm{kV}$ lines in 2007. Due to the success in eliminating phase-to-phase faults, about $28 \mathrm{~km}$ of double circuits were equipped in 2019 with these devices.

As there are some local areas that have recurrent service disruptions due to wet snow accretion, the applicability of thermal anti-icing was studied. Detailed load flow analysis showed that load shifting (method 6.1.1) would not allow obtaining the current magnitudes that would be needed to create sufficient heat in the conductors. Moreover, the installation of shunt reactors (method 6.1.3) at critical locations allowed the creation of sufficient current flow. Thus, the Italian network operator started a program for the installation of shunt reactors at different critical sites. It is noted that the addition of these shunt reactors might also be beneficial for voltage regulation in the local networks.

\subsection{Recent Applicability Studies in Norway}

A recent applicability study of anti-icing and de-icing technologies was presented by [15] for the Norwegian power grid. Presently, the main method for de-icing of power lines consists of the use of helicopters that strike the lines with a pole attached to an insulated rope (method 5.1.5). Several technologies were investigated in order to verify if they could be applied in the context with the specific conditions that prevail in Norway: mostly in-cloud icing, extremely non-uniform ice loads, sometimes only on a few spans, with difficult or no terrestrial access to the lines due to complex topography and remote areas. 
A workshop was organized in October 2018 where about 80 international specialists gathered and presented the current development state of various methods. Nine methods were retained for further analyses as these were considered potentially applicable to the Norwegian conditions. The following preliminary recommendations were formulated in [15] in order to identify the methods that should be further investigated:

- For ground wires, the use of remotely controlled external current sources that are permanently installed on critical line sections (method 6.2.2).

- For phase conductors, two methods are identified - current redistribution by contactors load transfer in bundled lines (method 6.5) and use of high frequency injection with generators installed on critical line sections (method 6.4).

- For fjord crossings, LC spirals seem to be an interesting option (method 4.2).

\subsection{Recommendations after the Winter Storm of January 2008 in China}

The important icing disaster in large parts of southern and central China in January and February 2008 led to intense research efforts and an important number of publications similar to the development that could be observed in Québec after the 1998 ice storm. As examples, two reviews $[4,16]$ were included in the present analysis. It should be mentioned that China experienced an increase in the high voltage DC line projects during the last years. Therefore, $\mathrm{Li}$ et al. [16] elaborated various technologies designed for thermal de-icing of DC power lines (method 6.3). Lv and He [4] concluded that the development of de-icing methods for power lines are expected to follow a trend towards mechanical de-icing based on robots (method 5.1.6).

In another publication by a joint team of experts from university and power companies [29], Jiang et al. reported on the strategies and status of anti-icing methods that were studied in China after the 2008 ice storm. Various countermeasures applying coatings, laser technologies, and robots as well as AC and DC de-icing techniques were tested. It was found that the thermal de-icing method using DC voltage (methods 6.2.3 and 6.3) is a convenient solution with relatively low power demand and high efficiency. According to Jiang et al. [29], more than 200 substations have been equipped with fixed DC de-icing systems and mobile ice-melting devices are also employed by various utilities. Two years later, Jiang et al. reported ongoing research efforts with emphasis on the load current transfer method of bundled conductors (method 6.5) [30].

\section{Conclusions}

The comparative analysis of several review papers and technical reports show that a large number of technologies were already proposed decades ago, before the catastrophic ice storms of 1998 in Eastern Canada and 2008 in central and southern China. The intense work within research institutions as well as utilities in the wake of these events led to the increase in the understanding of the meteorological phenomena and their impacts on the power grids. Rather than finding new technologies, efforts have been focused on developing already known countermeasures with the potential for practical application in field operations.

There is no single trend for the deployment of anti-icing or de-icing technologies around the world. Passive, thermal, and mechanical methods are used by utilities in various regions of the world, depending on their local needs and their local experiences in the past. Additionally, the recommendations for future applications are diverse. Regarding the construction of new lines or the reconstruction of damaged lines, several lessons have been learned since the catastrophic events in 1998 and 2008 and actions are taken today to improve the line design.

Once one or several anti-icing or de-icing methods have been selected for the integration into field operations, several years may pass before the deployment is accomplished. This should be considered in the deployment strategies. 


\section{Future Outlook}

There are three reasons why we should be seeking for affordable and long-term solutions against icing and snowing of power grids, a major problem that has attracted a global effort.

- With climate changes, power grids are poised to experience unpredicted icing and snowing events that may not be limited only to the so-called "cold regions".

- With increasing age, most installed transmission lines are more fragile.

- The ever-growing demand for electricity is another major concern that adds to the problem.

While active (heating, chemicals, and mechanical methods) solutions are widely used to remove ice or snow, passive solutions by nanotechnology are expected to affect the antiicing industry. Although coating solutions are already available, research in this area still needs to be pursued. Ongoing research will increase our knowledge of the fundamental mechanisms through which nanoparticles interact with freezing rains.

Key challenges include icing prevention for extended periods thereby decreasing the risk of potential damage to infrastructure and outdoor structures and concomitant lowering of related maintenance and replacement costs. Encapsulated phase change materials and superhydrophobicity [31] achieved by texturing a surface to develop novel coating platforms are promising candidates for developing robust anti-icing materials. Smart materials with a self-sustainable lubricating layer, achieved via modifying solid substrates or self-healing ones are also interesting alternatives [32]. The impact can be significant as various areas from the power grids to aerospace and sea vessels can benefit from the research results.

Author Contributions: Data collection and analysis, original draft preparation, Sections 2-5, S.B.; abstract, Sections 1 and 6, general review and editing, I.F. All authors have read and agreed to the published version of the manuscript.

Funding: This research received no external funding.

Institutional Review Board Statement: Not applicable.

Informed Consent Statement: Not applicable.

Data Availability Statement: Not applicable.

Conflicts of Interest: The authors declare no conflict of interest.

\section{References}

1. Pohlman, J.C.; Landers, P. Present State-of-the-Art of Transmission Line Icing. IEEE Trans. Power Appar. Syst. 1982, PAS-101, 2443-2450. [CrossRef]

2. Laforte, J.L.; Allaire, M.A.; Laflamme, J. State-of-the-Art on Power Line De-Icing. In Proceedings of the 7th International Workshop on Atmospheric Icing of Structures (IWAIS), Chicoutimi, QC, Canada, 3-7 June 1996.

3. Farzaneh, M. (Ed.) Atmospheric Icing of Power Networks, 1st ed.; Springer: Berlin/Heidelberg, Germany, 2008.

4. Lv, X.; He, Q. Analysis of Dicing Techniques and Methods of Overhead Transmission Line. Procedia Eng. 2011, 15, 1135-1139. [CrossRef]

5. Quaia, S.; Marchesin, A.; Rampazzo, D.; Mancuso, C. Anti-Icing Measures in the Italian Power System. IET Gener. Transm. Distrib. J. 2019, 13, 5577-5585. [CrossRef]

6. CEATI. De-Icing Techniques before, during, and Following Ice Storms; Technical Report T003700-3303; CEA Technologies Inc.: Montreal, QC, Canada, 2002.

7. Volat, C.; Farzaneh, M.; Leblond, A. De-icing/Anti-icing Techniques for Power Lines: Current Methods and Future Direction. In Proceedings of the 11th International Workshop on Atmospheric Icing of Structures (IWAIS), Montréal, QC, Canada, 13-16 June 2005.

8. Farzaneh, M.; Volat, C.; Leblond, A. Anti-icing and de-icing techniques for overhead lines. In Atmospheric Icing of Power Networks, 1st ed.; Farzaneh, M., Ed.; Springer: Berlin/Heidelberg, Germany, 2008; pp. 229-268.

9. CIGRÉ WG B2.29. Systems for Prediction and Monitoring of Ice Shedding, Anti-Icing and De-Icing for Power Line Conductors and Ground Wires; Technical Brochure No. 438; International Council on Large Electric Systems: Paris, France, 2010. 
10. Solangi, A.R. Icing Effects on Power Lines and Anti-Icing and De-Icing Methods. Master's Thesis, UiT The Arctic Univeristy of Norway, Tromsø, Norway, 2018.

11. Farzaneh, M. Impact and Mitigation of Icing on Power Network Equipment. Available online: https://www.inmr.com/impactmitigation-icing-power-network-equipment/ (accessed on 9 June 2021).

12. Régie de l'Énergie du Québec, Public Hearing R-3522-2003, HQT-12 Document 1, Responses to Request for Information no. 1 from the Régie de l'Énergie, 15 April 2004. Available online: http:/ / www.regie-energie.qc.ca/audiences/3522-03/RepDemRens/ HQT-12_doc1_3522-03_16avr04.pdf/ (accessed on 28 May 2021).

13. Régie de l'Énergie du Québec, Public Hearing R-3522-2003, HQT-12 Document 3, Responses to Request for Information from the Union of Consumers, 15 April 2004. Available online: http:/ / www.regie-energie.qc.ca/audiences/3522-03/RepDemRens/HQT12_doc3_3522-03_15avr04.pdf/ (accessed on 28 May 2021).

14. Prud'Homme, P.; Dutil, A.; Laurin, S.; Lebeau, S.; Benny, J.; Cloutier, R. Hydro-Québec TransÉnergie Line Conductor De-Icing Techniques. In Proceedings of the 11th International Workshop on Atmospheric Icing of Structures (IWAIS), Montréal, QC, Canada, 13-16 June 2005.

15. Gutman, I.; Lundengard, J.; Naidoo, V.; Adum, B. Technologies to Reduce and Remove Ice from Phase Conductors and Shield Wires: Applicability for Norwegian Conditions. In Proceedings of the 18th International Workshop on Atmospheric Icing of Structures (IWAIS), Montréal, QC, Canada, 19-23 June 2019.

16. Li, S.; Wang, Y.; Li, X.; Wei, W.; Zhao, G.; He, P. Review of De-icing Methods for Transmission Lines. In Proceedings of the 2010 International conference on Intelligent System Design and Engineering Applications, Changsha, China, 13-14 October 2010. [CrossRef]

17. Twenty Years Ago, Québec Was Battered by an Ice Storm. Available online: http://news.hydroquebec.com/en/press-releases/ 1313/twenty-years-ago-quebec-was-battered-by-an-ice-storm/ (accessed on 22 August 2021).

18. Régie de l'Énergie du Québec, Public Hearing R-3522-2003, Expert Report by G. Olivier for the Union of Consumers, 4 May 2004. Available online: http:/ / www.regie-energie.qc.ca/audiences/3522-03/PreuveInterv/UC_Preuve_RapportExpertise_3522_0 5mai04.pdf/ (accessed on 27 May 2021).

19. CIGRÉ WG B2.44. Coatings for Protecting Overhead Power Network Equipment in Winter Conditions; Technical Brochure No. 631; International Council on Large Electric Systems: Paris, France, 2015.

20. CIGRÉ WG B2.69. Coatings for Protecting Overhead Power Networks against Icing, Corona Noise, Corrosion and Reducing Their Visual Impact; Technical Brochure No. 838; International Council on Large Electric Systems: Paris, France, 2021.

21. Régie de l'Énergie du Québec, Public Hearing R-3522-2003, D-2004-175, Decision of the Régie de l’Énergie du Québec, 20 August 2004. Available online: http:/ / www.regie-energie.qc.ca/audiences/decisions/D-2004-200.pdf/ (accessed on 2 August 2021).

22. Hydro-Québec. Rapport Annuel 2005; @ Hydro-Québec: Montreal, QC, Canada, 2006; ISBN 2-550-46386-2. (In French)

23. Hydro-Québec. Rapport Annuel 2008; @ Hydro-Québec: Montreal, QC, Canada, 2009; ISBN 978-2-550-55045-7. (In French)

24. Hydro-Québec. Rapport Annuel 2017; @ Hydro-Québec: Montreal, QC, Canada, 2018; ISBN 978-2-550-80380-5. (In French)

25. Hydro-Québec. Rapport Annuel 2010; @ C Hydro-Québec: Montreal, QC, Canada, 2011; ISBN 978-2-550-60867-7. (In French)

26. Hydro-Québec. Rapport Annuel 2012; @ C Hydro-Québec: Montreal, QC, Canada, 2013; ISBN 978-2-550-66871-8. (In French)

27. After 1998: A More Robust Grid. Available online: https://www.hydroquebec.com/ice-storm-1998/after-the-storm.html (accessed on 22 August 2021).

28. Hydro-Québec. Rapport sur le Développement Durable 2011; @ C Hydro-Québec: Montreal, QC, Canada, 2012; ISBN 978-2-550-63874-2. (In French)

29. Jiang, X.; Dong, B.; Dong, L.; Lu, J.; Zhang, J. Strategies and Status of Anti-Icing and Disaster Reduction for Power Grid after the 2008: Ice Storm in China. In Proceedings of the 15th International Workshop on Atmospheric Icing of Structures (IWAIS), St. Johns, NL, Canada, 8-11 September 2013.

30. Jiang, X.; Wang, Y.; Shu, L.; Zhang, Z.; Hu, Q.; Wang, Q. Control scheme of the de-icing method by the transferred current of bundled conductors and its key parameters. IET Gener. Transm. Distrib. J. 2015, 9, 2198-2205. [CrossRef]

31. Amir, A.Y.; Anahita, A.; Khosrow, M.; Reza, J.; Gelareh, M. Potential anti-icing applications of encapsulated phase change material-embedded coatings; a review. J. Energy Storage 2020, 31, e101638.

32. Gong, H.; Yu, C.; Zhang, L.; Xie, G.; Guo, D.; Luo, J. Intelligent lubricating materials: A review. Compos. Part B Eng. 2020, 202, 108450. [CrossRef] 